\title{
EFFECT OF RIBLETS AND SUCTION ON A FLAT PLATE TURBULENT BOUNDARY LAYER
}

\begin{abstract}
M. O. Oyewola ABSTRACT
This work presents hot-wire measurements in a flat plate turbulent boundary University of Newcastle layer, subjected to the combination of riblets and suction. The suction is applied through a porous strip for a range of suction rates. The effect of riblets and suction has been quantified through the measurements of mean velocity and Reynolds stresses downstream of the suction strip on the riblets surface. The results of the mean velocity and Reynolds stresses indicate that there is no significant change in the distributions of riblets and smooth wall. However, there exist some changes with the combination of suction and riblets relative to the smooth surface. These changes arise from the interference of suction with the mechanism of the layer. The results suggest that riblets may not alter the effect suction has on the boundary layer structures.
\end{abstract}

Keywords: boundary layer, suction, riblets, measurements

\section{NOMENCLATURE}

$A_{w} \quad$ cross-sectional area

$b \quad$ width of the strip, $\mathrm{m}$

$D$ pipe diameter, $\mathrm{m}$

$h$ height of the groove, $\mathrm{m}$

$L \quad$ pipe length, $\mathrm{m}$

$p$ pressure, $\mathrm{N} / \mathrm{m}^{2}$

$Q_{r} \quad$ flow rate, $\mathrm{m}^{3} / \mathrm{s}$

$R_{\theta o} \quad$ Reynolds number based on momentum thickness without suction, $U_{1} \theta_{0} / v$

$s \quad$ length of the groove, $\mathrm{m}$

$\mathrm{u}, \mathrm{v}, \mathrm{w}$ velocity components, $\mathrm{m} / \mathrm{s}$

$\mathrm{U}$ mean velocity, $\mathrm{m} / \mathrm{s}$

$\mathrm{U}_{1} \quad$ free stream velocity, $\mathrm{m} / \mathrm{s}$

$\mathrm{U}$ friction velocity, $\mathrm{m} / \mathrm{s}$

$\mathrm{V}_{\mathrm{w}} \quad$ suction velocity, $\mathrm{m} / \mathrm{s}$

$\mathrm{x}, \mathrm{y}, \mathrm{z}$ cartesian coordinates, $\mathrm{m}$

\section{Greek symbols}

$\sigma \quad$ normalized suction rate (severity index)

$\delta \quad$ boundary layer thickness, $\mathrm{m}$

$\theta \quad$ momentum thickness, $\mathrm{m}$

$\theta_{o} \quad$ momentum thickness without suction, $\mathrm{m}$

$v$ fluid kinematic viscosity, $\mathrm{m}^{2} / \mathrm{s}$

$\rho \quad$ density, $\mathrm{kg} / \mathrm{m}^{3}$

$\tau_{w} \quad$ wall shear stress, $\mathrm{N} / \mathrm{m}^{2}$

\section{INTRODUCTION}

The control of turbulent boundary layer by interfering with the turbulence structures is of engineering importance and benefit. Such effect can lead to drag reduction, delay of transition, separation control, etc. (Gad-el-hak, 1989). Liapman (1979) as reviewed by Hefner et al. (1980) stated that probably the most important aspect of the existence of deterministic structures in turbulent flow is the possibility of turbulence control by direct interference with large structures. Kim (1992) proposed the near-wall streamwise vortex as the most relevant turbulence structure from the perspective of drag reduction in turbulent boundary layers. In that respect, the use of passive and active means to manipulate the response of the boundary layers has attracted quite a number of studies (Bushnell et al., 1984; Pimenta et al., 1979; Gad-elHak, 1989). The general consensus indicates that passive control can be used to reduce the skin friction and active control to delay flow separation or postpone transition.

Considerable efforts have been devoted to the study of the riblets in a turbulent boundary layer (Walsh, 1990; Park and Wallace, 1994; Djenidi and Antonia, 1996). It has been well established that relative to the smooth wall boundary layer, riblets can reduce the frictional drag of a turbulent boundary layer. For example, Djenidi and Antonia (1996) in their Laser Doppler Anemometer (LDA) measurements found that the influence of the riblets surface on the near-wall turbulence structure differs, according to whether the riblets reduce or increase the skinfrictional drag relative to a smooth wall. They found that while the Reynolds stress tensor over drag-reducing riblets was only marginally different from that on a smooth wall, the Reynolds stresses under drag-augmenting conditions are larger and the flow is more isotropic than on a smooth wall.

Moreover, the effect of suction applied through a single narrow porous strip on a boundary layer is of significantly important especially in delaying transition 
and relaminarisation (Oyewola et al., 2003; Antonia et al., 1995). Antonia et al. (1995) studied the effect of concentrated wall suction applied through a short porous wall strip, on a low Reynolds number turbulent boundary layer. They showed that, when the suction rate is sufficiently high, pseudo-relaminarization occurred almost immediately downstream of the suction strip. Further downstream, transition occurs followed by a slow return to a fully turbulent state. During relaminarization, the measured skin friction coefficient $\mathrm{C}_{\mathrm{f}}$ falls below the level corresponding to the no suction value. They found that recovery rate differs among the three Reynolds stress they measured: the longitudinal Reynolds stress $\left\langle u^{2}\right\rangle$ is the first to return to the fully turbulent state, while the Reynolds shear stress $-\langle u v\rangle$ is the slowest to recover. Recently, Oyewola et al. (2003) extends the work of Antonia et al. (1995) and carried out experiments on the combined influence of the Reynolds number and localised wall suction on a turbulent boundary layer. They found that both the suction rate, $\sigma$, and the momentum thickness Reynolds number, $\mathrm{R}_{\theta}$ played important role in the relaminarisation process. They argued that the ratio $R_{\theta_{0}} / \sigma$ should not exceed a (as yet undetermined) critical value if relaminarisation is to occur. Similarly, Oyewola (2004) carried out the experimental investigation of the influence of riblets on the suction effect on a turbulent boundary through the measurements of mean velocity and velocity fluctuation in the streamwise direction. His measurements are not wide in scope to fully quantify the influence of riblets on the suction effect.

The main focus of this present work, which extends the work of Oyewola (2004), is on the experimental investigation of the effect of riblets and suction on a flat plate turbulent boundary layer. This effect is quantifying through the measurements of mean velocity and Reynolds stresses for various stations downstream of the suction strip over the riblets surface and for a range of suction rates. The results are compared with the smooth and riblets surfaces when no suction is applied.

\section{EXPERIMENTAL DETAILS}

Experiments were carried out in an open return, suction type wind tunnel driven by an axial flow fan that was powered by a controllable DC motor. Air enters the working section (Figure 1) via a bell mouth inlet, a honeycomb section, a short settling chamber fitted with screens and a 5: 1 two-dimensional contraction. The working section was followed by a two-dimensional diffuser and a transition section immediately upstream of the fan casing and recovery diffuser. The turbulent boundary layer develops on the floor of the rectangular working section (Figure 1) after it is tripped at the exit from the contraction using a $100 \mathrm{~mm}$ roughness strip. Tests showed that the boundary layer was fully developed at the suction strip location, which is about $710 \mathrm{~mm}$ downstream of the roughness strip and $340 \mathrm{~mm}$ upstream of the leading edge of the riblet section. The first $1 \mathrm{~m}$ section of the wall was smooth (Fig. 1). The next $1 \mathrm{~m}$ consisted of the riblet surface; longitudinal triangular grooves $(\mathrm{h}=\mathrm{s}=2.5 \mathrm{~mm})$ machined out of aluminium covering the complete span of the working section. The last $1 \mathrm{~m}$ section of the wall was again smooth. The plane of the riblet crest was flush with the smooth surfaces. Reference smooth wall measurements were obtained by placing a $3 \mathrm{~mm}$ thick sheet of Laminex over the riblet section. The leading edge $(\mathrm{x}=0.65 \mathrm{~m})$ of the sheet was tapered down to a thin wedge in order to minimize any disturbances at the measurement stations. In this manner the measurements with and without the riblets were carried out at the same conditions. Measurements were made at $U_{1}$ of $3.35 \mathrm{~ms}^{-1}$; the corresponding value of the initial momentum thickness Reynolds number $\mathrm{R}_{\theta_{\mathrm{o}}}$ was 750 . A $3.25 \mathrm{~mm}$ thick porous strip with a width of $40 \mathrm{~mm}$ and made of sintered bronze with pore sizes in the range $4080 \mu \mathrm{m}$ or $\left(\begin{array}{ll}\theta .4 & 0.9\end{array}\right) \mathrm{v} / \mathrm{U}_{\tau}$ was mounted flush with the test section floor. Allowing for the width of the mounting recess step, the effective width $(=\mathrm{b})$ of the strip was $35 \mathrm{~mm}$. Suction was applied through a plenum chamber located underneath the suction strip and connected to a vacuum pump, through a circular pipe $(L / D$ $\approx 40$, where, $\mathrm{L}$, is the pipe length and $\mathrm{D}$ is the internal diameter). The flow rate $\mathrm{Q}_{\mathrm{r}}$ was estimated directly from the pressure drop across the orifice. The suction velocity $\left(\mathrm{V}_{\mathrm{w}}\right)$ was inferred via the continuity equation $\left(Q_{r}=A_{w} V_{w}\right.$, where, $\mathrm{A}_{\mathrm{w}}$ is the cross-sectional area of the porous strip). The suction velocity was assumed to be uniform over the porous surface; this assumption seems reasonable if the variation in the permeability coefficient of the porous material is $\pm 3 \%$.
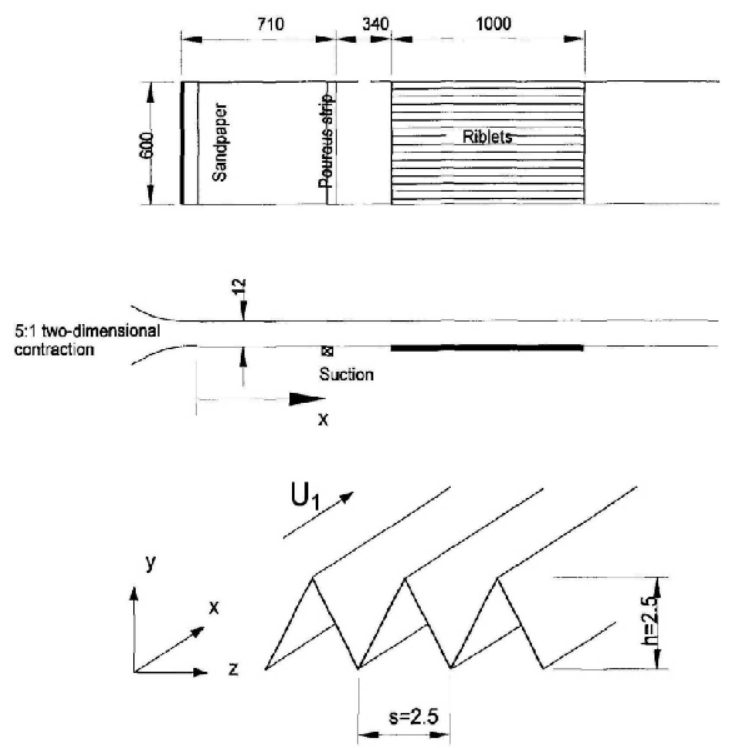

Figure 1: Schematic arrangement of the working section

Measurements were made for $\sigma$ (normalised suction rate, severity index as introduced by Antonia et al., $\left.1995=V_{w} b / \theta_{o} U_{l}\right)=0,1.7,3.3$ and 5.5. The results at $=0$ provided a reference against which the suction data could be appraised. The wall shear stress $\tau_{\mathrm{w}}$ in the smooth wall boundary layer was measured with a Preston tube $(0.72$ $\mathrm{mm}$ outer diameter), and a static tube located approximately $35 \mathrm{~mm}$ above it at the same $\mathrm{x}$ position. The results are compared to those obtained by Clauser chart. The variation is less than $5 \%$. No attempt was made to measure the wall shear stress over the riblets. The smooth wall friction velocity was used to normalize the riblets data. The mean velocity was measured with a single hot wire. Measurements of the velocity fluctuations in the streamwise and wall normal directions were made with cross wires, each inclined at $45^{\circ}$ to the flow direction. The etched portion of each wire (Wollaston, Pt-10\% Rh) had a diameter of $2.5 \mu \mathrm{m}$, and a length to diameter ratio of about 200. The separation between the inclined wires was about $0.6 \mathrm{~mm}$. All hot wires were operated with in-house 
constant temperature anemometers at an overheat ratio of 1.5. The analog output signal of the hot wire was low pass filtered at $3.5 \mathrm{kHz}-5 \mathrm{kHz}$, offset and amplified to within \pm 5 V.

\section{RESULTS AND DISCUSSION}

Figure 2 shows the distribution of the mean velocity profiles. Since the local value of friction velocity value $U_{\tau}$ over the riblets are not measured and to avoid confusion associated with the measurements of the $U_{\tau}$, outer normalization $\left(U_{1}\right.$ for the velocity scale, $\delta$ for the length scale) is used. The data for the smooth wall in the absence of riblets and suction is also included against which the effect of suction and riblets can be assessed.

While for all the stations shown, the mean velocity collapse reasonably well in the region $\mathrm{y} / \delta<0.15$, reflecting the rapid response of the mean velocity in this region to a change in the boundary conditions. However, there is noticeable modification to the mean velocity profile in the region $y / \delta \geq 0.15$. For example relative to the smooth wall, in the absence of suction, the riblets shows almost similar modification to the mean velocity in all the stations, suggesting that the riblets act in the same mode of operation. In case of suction and riblets, the mean velocity shift upward in the region $0.2<\mathrm{y} /<0.7$; the effect is increased as the suction rate is increased. This implies that the tendency towards the flow being relaminarised increases as the suction rate increases. This is not surprising, since relaminarisation can be achieved for appropriate combination of Reynolds number and suction rate (Oyewola et al., 2003). The result would suggest that relaminarisation may possibly occur in this present study $\left(\mathrm{R}_{\theta_{\mathrm{o}}}=750\right)$ at least when $\sigma=5.5$ as reflected in the upward shift in the log-law region. This shift would be more pronounce if the friction velocity is used to normalize the mean velocity. The result is similar to what was observed in the turbulent boundary layer subjected to the concentrated suction alone (Oyewola et al., 2003). Oyewola et al. (2003) found that the log-law region of the boundary layer is strongly perturbed by suction; the magnitude of the perturbations is increased as the suction rate is increased. Moreover, as $\mathrm{x} / \delta$ increases, the effect of suction and riblets, which appear in the region $y / \delta \geq 0.15$, gradually decreases, suggesting a recovery to the undisturbed boundary layer. The result would suggest that riblets do not affect the effect of suction on the boundary layer.

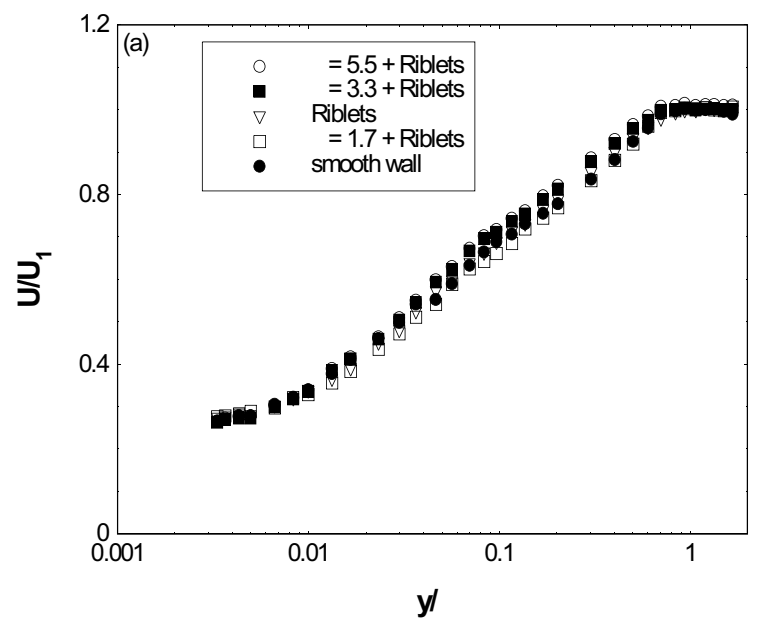

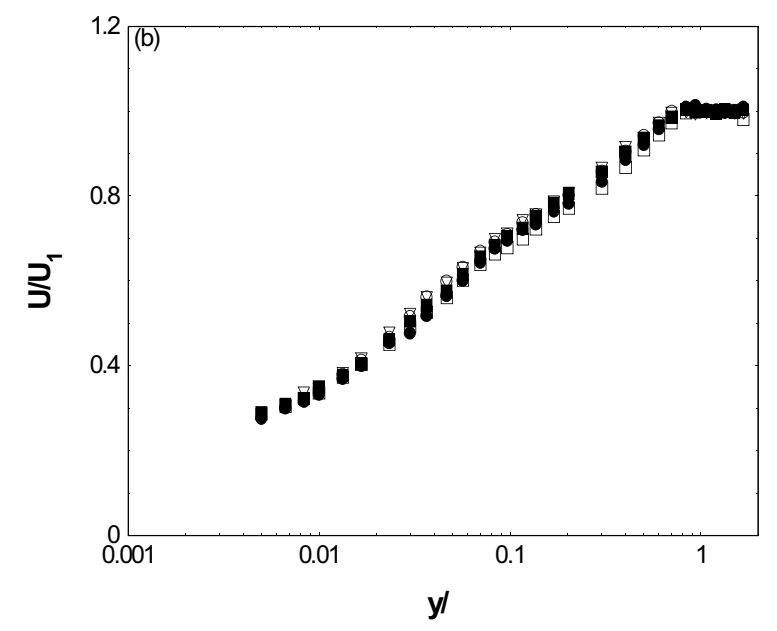

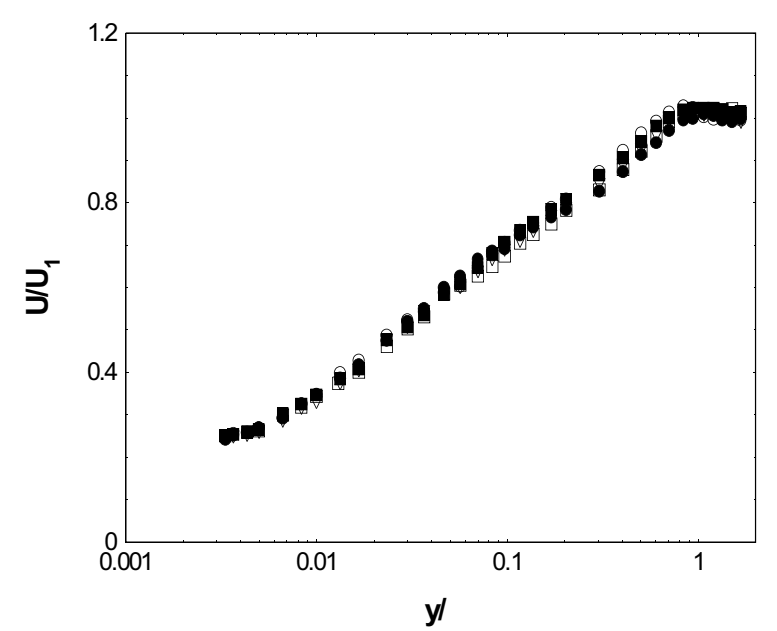

Figure 2. Distribution of normalised mean velocity. (a) $x$

$$
/=5 \text {; (b) } 10 \text {; (c) } 15 \text {. }
$$

While the previous mean velocity distributions suggest that riblets may not influence the effect suction has on the boundary layer, this is confirmed in the streamwise variation of the Reynolds stress $<\mathrm{u}^{2}>/ \mathrm{U}_{1}{ }^{2}$ plotted in the outer scaling and shown in Figure 3. Interestingly, while the riblets data collapse reasonably well with the smooth wall data near the wall, the combination of the suction and riblets data depart from the smooth wall data at $\mathrm{x} / \delta=5$ when $\sigma=3.3$ and 5.5. This implying that the turbulent field responds less quickly to a change in boundary conditions than the mean field. The departure of the combination of suction and riblets from the smooth wall data would suggest a weakening of the active motion and to a lesser degree inactive motion, and these would result in a change in the turbulence structures. The distributions of $<\mathrm{v}^{2}>/ \mathrm{U}_{1}{ }^{2}$ and $-<\mathrm{uv}>/ \mathrm{U}_{1}{ }^{2}$ (Figures $4 \& 5$ ) provide support for the latter suggestion. This is not surprising since $\left\langle v^{2}\right\rangle$ receives it contribution from active motion and $\left\langle\mathrm{u}^{2}>\right.$ from inactive motion. It should be noted that the changes in the distributions of $\left\langle\mathrm{u}^{2}\right\rangle / \mathrm{U}_{1}{ }^{2},\left\langle\mathrm{v}^{2}\right\rangle / \mathrm{U}_{1}{ }^{2}$ and $-<\mathrm{uv}>/ \mathrm{U}_{1}{ }^{2}$ relative to no suction case, arise as a result of the manipulating effect of suction on the boundary layer structures. This imply that the near-wall coherent structures has been interfered with by suction, giving rise to a structure of reduce intensity downstream of the suction strip. This argument is consistent with the reduction of $<\mathrm{u}^{2}>/ \mathrm{U}_{1}^{2},<\mathrm{v}^{2}>/ \mathrm{U}_{1}{ }^{2}$ and $-<\mathrm{uv}>/ \mathrm{U}_{1}{ }^{2}$ when $\sigma=3.3$ and 5.5 and at $x /=5$. The result would suggest that psuedorelaminarisation occur at these suction rates. This is 
in agreement with Antonia et al. (1995) and Oyewola et al. (2003) who found that relaminarisation occur when $\sigma \geq 2.6$. Interestingly, at $\mathrm{x} / \delta=5$ (Figure $5 \mathrm{a}$ ),,$-<\mathrm{uv}>/ \mathrm{U}_{1}^{2}$ decreases towards the negative values in the near-wall region. This may be a result of the suppression by suction, of the injection of the fluid between the cavities of the groove of the riblets to the boundary layer. This is not surprising, since streamwise vortices, which are present in this region are likely to be weakened or even eradicated by suction. The results would suggest that the momentum exchange between the wall and the flow in the boundary layer was so intense. These imply that the momentum is gain by the flow in this part of the boundary layer, at the detriment of the wall. The effect increases as the suction increases.

The departure of the outer region from the smooth wall reflects the difference in the Reynolds number between the perturbed and unperturbed boundary layers. The results are representative of those observed when suction act alone on the boundary layer (Oyewola et al., 2003). The present results would suggest that riblets do not change the actual mechanism upon which suction act on the boundary layer. As expected, the effect of suction and riblets reduces as $\mathrm{x} / \delta$ increases. For example, at $\mathrm{x} / \delta=15$, all the data collapses well both in the inner and outer regions with the exception of the local peaks. This suggests an increase in the Reynolds number of typical rough wall flows. Antonia et al. (1995) showed that the recovery proceeds at different rates between the different Reynolds stresses: $\left\langle u^{2}\right\rangle$ appears to be the quickest to recover. The combination of suction and riblets, while altering the individual rates of recovery, does not change the relative order of recovery between the Reynolds stresses.
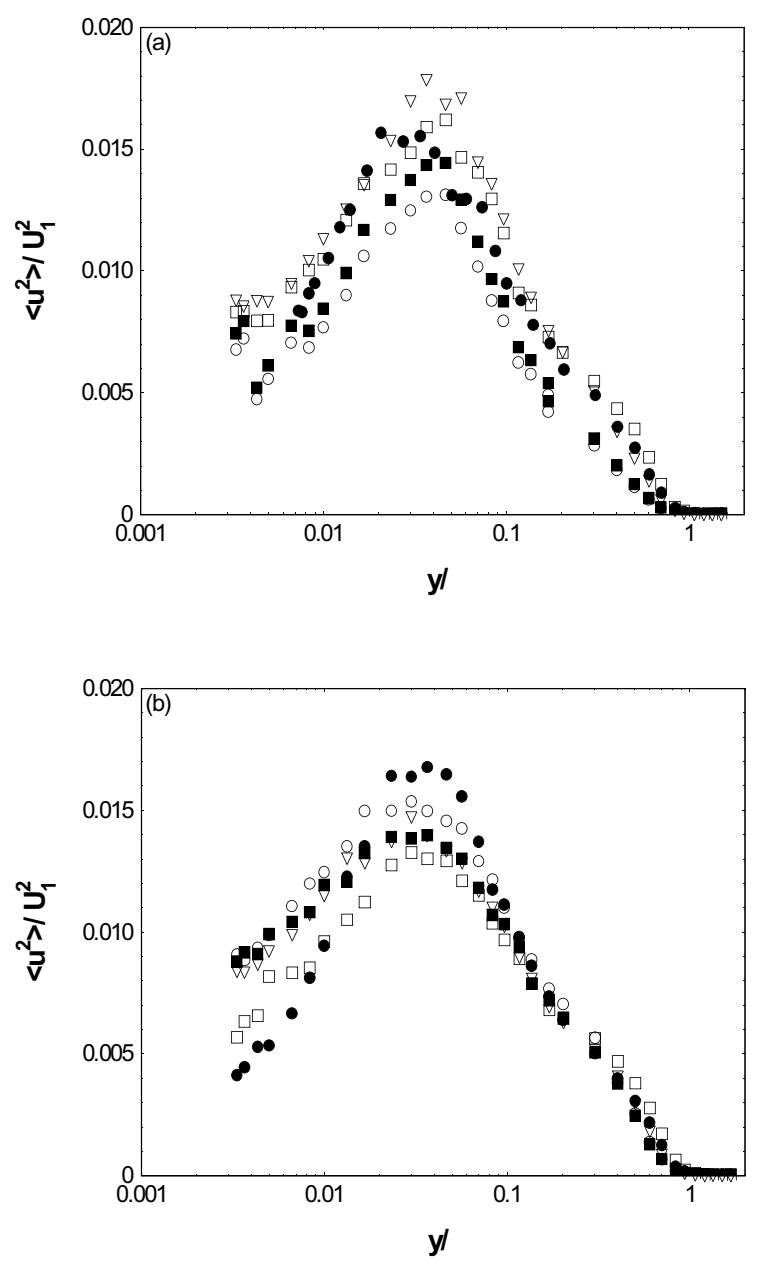

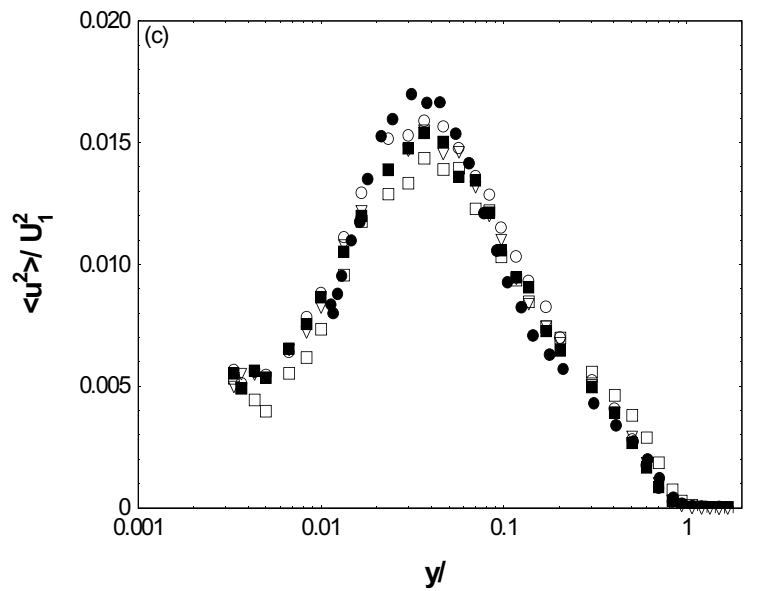

Figure 3. Streamwise variation of normalised longitudinal Reynolds stress $<\mathrm{u}^{2}>/ \mathrm{U}_{1}^{2}$. (a) $\mathrm{x} / \delta=5$; (b) 10 ; (c) 15. Symbols are as in Figure 2.
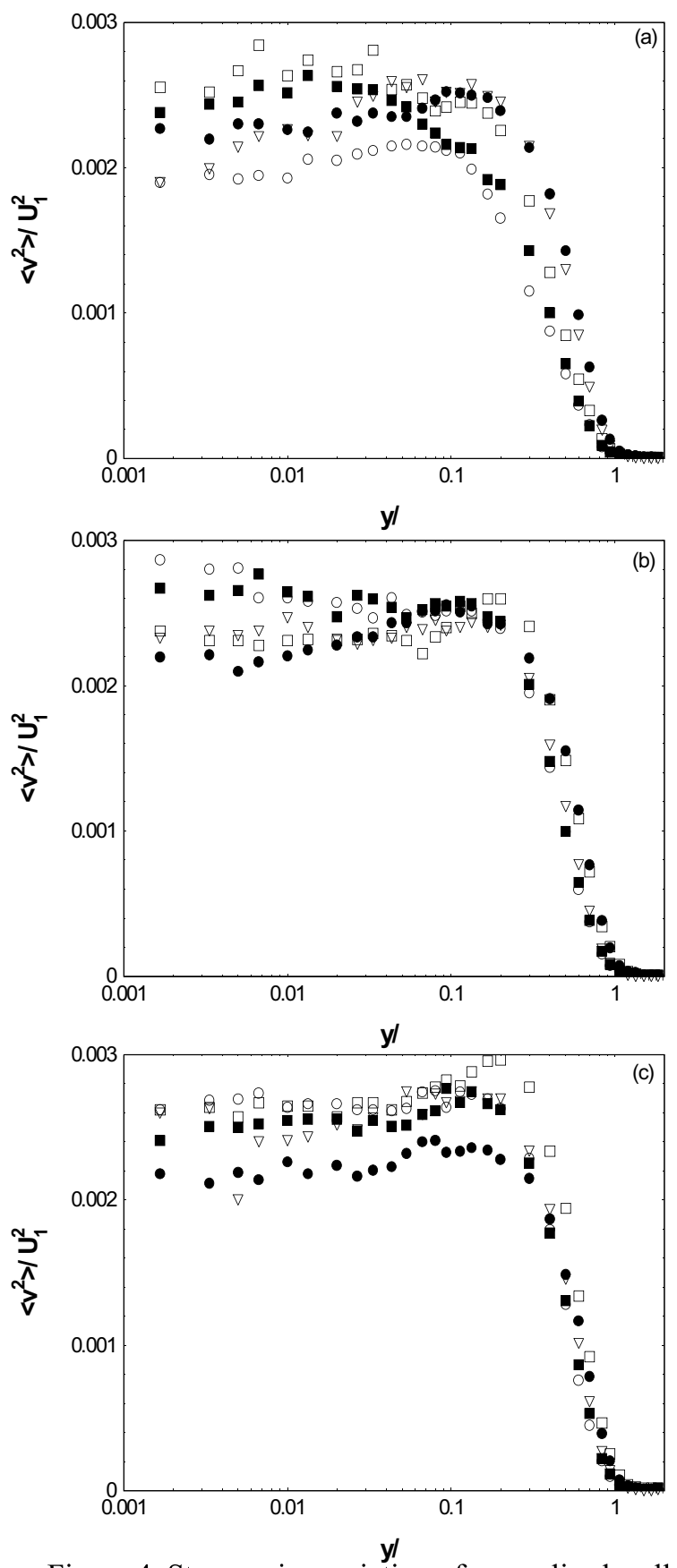

Figure 4. Streamwise variation of normalised wallnormal Reynolds stress $\left\langle\mathrm{v}^{2}>/ \mathrm{U}_{1}^{2}\right.$. (a) $\mathrm{x} /=5$; (b) 10 ; (c) 15. Symbols are as in Figure 2. 

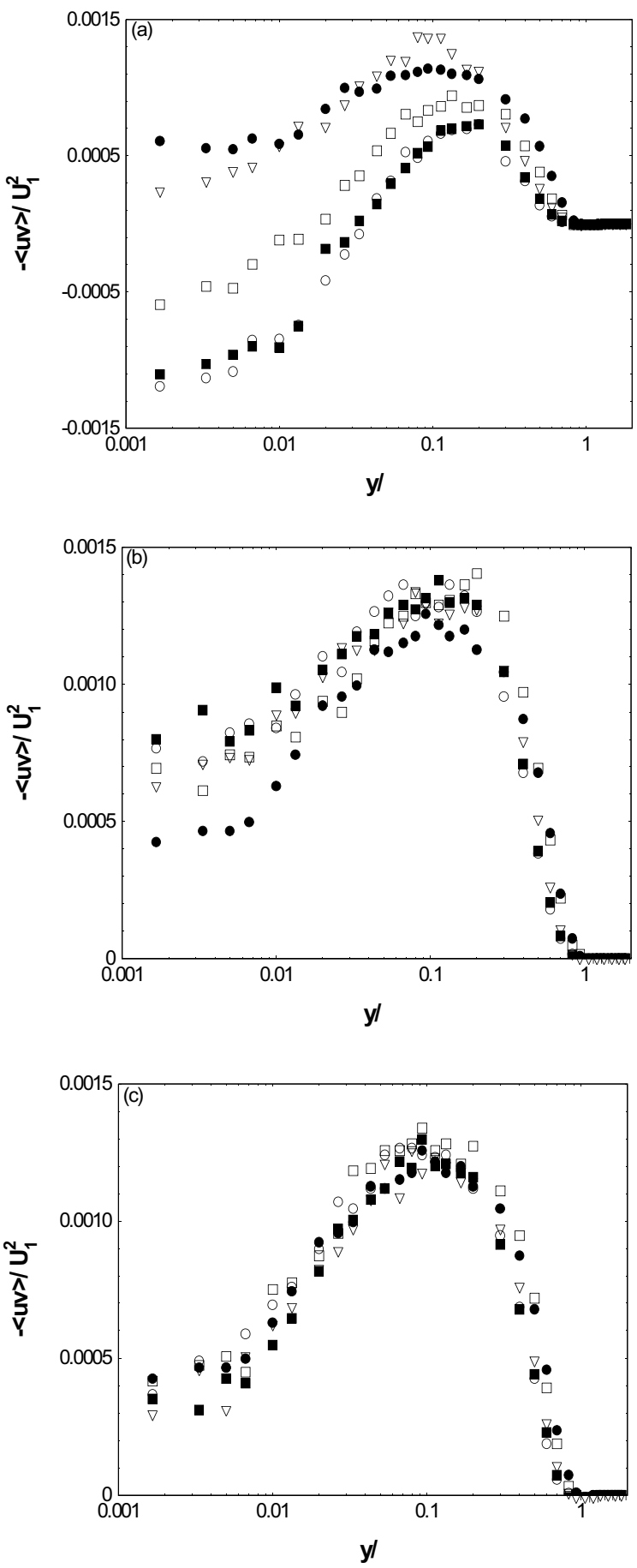

Figure 5. Streamwise variation of normalised Reynolds shear stress $-<u v>/ U_{1}^{2}$. (a) x / = 5; (b) 10; (c) 15 . Symbols are as in Figure 2

\section{CONCLUSIONS}

In this work, an experimental study was conducted to demonstrate the effect of riblets and suction in a flat plate turbulent boundary layer. Measurements were made over riblet surface without suction and with suction in the range $0 \leq \sigma \leq 5.5$. The results indicate that, while the mean velocity and Reynolds stresses distributions of the riblets and smooth wall showed no significant differences, the combination of suction and riblets depart considerably from their smooth wall data. The results suggest that riblets may not alter the effect of suction on the mechanism of the layer. The reduction of the Reynolds stresses by the combination of suction and riblets suggest a weakening of the active motion and to a lesser degree in active motion. The weakening is a result of the manipulating effect of suction on the boundary layer structures. The magnitude is increased as the suction rate is increased. The combination of suction and riblets, while altering the individual rates of recovery, does not change the relative order of recovery between the Reynolds stresses.

\section{ACKNOWLEDGEMENTS}

The author gratefully acknowledged the support of Prof Antonia and Dr. Djenidi. Also, the assistant of Miss Yemisi Ogunlola is gratefully acknowledged.

\section{REFERENCES}

Antonia, R. A., Zhu, Y., Sokolov, M., 1995, Effect of concentrated wall suction on a turbulent boundary layer, Physics of Fluids, Vol.7, pp. 2465-2475.

Bushnell, D. M., Anders, J. B., Walsh, M. J., Mcinville, R. V., 1984, Turbulent drag reduction research, AGARD Conference Proceedings no 365.

Bradshaw, P., 1967, Inactive motion and pressure fluctuations in turbulent boundary layers, Journal of Fluid Mechanics, Vol.30, pp. 241-258.

Cantwell, B. J., 1981, Organized motion in turbulent flow, Annual Review of Fluid Mechanics, Vol. 13, pp. 457.

Djenidi, L., Antonia, R. A., 1996, Laser doppler anemometer measurements of turbulent boundary layer over a riblet surface, American Institute of Aeronautics and Astronautics, Vol.34,pp. 1007-1012.

Djenidi, L., Vincent, A., Gall, P-E., Antonia, R. A., 2002, Effect of wall suction on the structure of a turbulent boundary layer, Proceedings of the $11^{\text {th }}$ Int. Symp. on the Application of Laser Techniques to Fluid Mechanics, Lisbon, Portugal, 8-11 July, 23-1 (available on CD ROM Ponteiromágico, electronic edition, LDA, Lisbon).

Gad-el-hak, M., 1989, Flow control, Applied Mechanics Review, Vol.42, pp. 261-293.

Hefner, J. N., Weinstein, L. M., Bushnell, D. M., 1980, Large-eddy breakup scheme for turbulent viscous drag reduction, Viscous Flow Drag Reduction edited by Hough, G.R., Progress in Astronautics and Aeronautics, Vol.72,pp. 110-127.

Kim, J., 1992, Study of turbulence structure through numerical simulations: the perspective of drag reduction, AGARD Report (R-786), AGARD FDP/VKI Special course on Skin Friction Drag Reduction, March 2-6, VKI, Brussels, Belgium.

Liepmann, H. W., 1979, The rise and fall of ideas in turbulence," American Scientist, Vol.67, March-April, pp. 221-228

Merigaud, E., Anselmet, F., Fulachier, L., Pailhas, G., Cousteix, J., 1996, Reduction of parasitic effects related to the turbulent boundary layer on the fuselage using slot suction, Emerging Techniques in Drag Reduction edited by K-S Choi, K. K. Prasad and T. V. Truong, pp. 263280.

Oyewola, M. O, 2004, Influence of riblets on the suction effect on a turbulent boundary layer, Proceedings of the $10^{\text {th }}$ Brazilian Congress of Thermal Sciences and Engineering, Paper No 0620.

Oyewola, O., Djenidi, L., Antonia, R. A., 2003, Combined influence of the Reynolds number and localised wall suction on a turbulent boundary layer, Experiments. in Fluids, Vol.35, pp. 199-206.

Park, S. Y., Wallace, J. M., 1994, Flow alteration and 
drag reduction by riblets in a turbulent boundary layer, American Institute of Aeronautics and Astronautics, Vol.32,pp. 31-38.

Pimenta, M. M., Moffat, R. J., Kays, W. M., 1979, The structure of a boundary layer on a rough wall with blowing and heat transfer, Journal of Heat Transfer, Vol.101, pp. 193-198.

Spalart, P. R., 1988, Direct simulation of a turbulent boundary layer up to $\mathrm{R}=1410$, Journal of Fluid Mechanics, Vol.187, pp. 61-98.

Walsh, M. J., 1990, Riblets, Viscous Drag Reduction in Boundary Layers: Progress in Astronautics and Aeronautics, Bushnell, D.M. and Hefner, J.N. (Eds), pp. 203. 